\title{
O círculo vicioso da corrupção no Brasil: limites estruturais e perspectivas de rompimento
}

José Antonio Gomes de Pinho

Universidade Federal da Bahia (UFBA)

Em pós doutoramento na Fundação Getulio Vargas (FGV-EAESP)

Ana Rita Silva Sacramento

Faculdade Anísio Teixeira

O escopo deste artigo consistiu em identificar e analisar aspectos do contexto socioeconômico e político do Brasil redemocratizado que reforçam ou ameaçam de rompimento o historicamente construído círculo vicioso da corrupção que o envolve. Por meio de pesquisa qualitativo-interpretativista, que possibilitou um plano de sustentação argumentativo relacionando aspectos teóricos do patrimonialismo e do rent seeking com informações empíricas do contexto histórico e sociopolítico-econômico do Brasil, concluiuse que: a corrupção no Brasil tem avançado aceleradamente nas últimas décadas, apesar da implantação de instituições e leis de combate ao fenômeno; não se vislumbra, pelo menos no médio prazo, possibilidade concreta de rompimento desse círculo vicioso; e que, na escala construída neste artigo, o país permanece nos postos elevados da classificação, configurado como um Estado e sociedade com fortes traços extrativistas de caráter perene.

Palavras-chave: corrupção, administração pública - Brasil

[Artigo recebido em 31 de março de 2018. Aprovado em 5 de dezembro de 2018.] 


\section{El Círculo Vicioso de la Corrupción en Brasil: límites estructurales y perspectivas de ruptura}

El alcance de este artículo se constituye en identificar y analizar aspectos del contexto socio económico y político de Brasil redemocratizado que refuerzan o amenazan el rompimiento históricamente construido círculo vicioso de la corrupción que lo envuelve. A través de investigación qualitativo-interpretativista, que posibilitó un plano de sustentación argumentativo relacionando aspectos teóricos del patrimonialismo y del rent seeking con informaciones empíricas del contexto histórico y socio político económico de Brasil, se concluye que: la corrupción en Brasil ha avanzado aceleradamente en las últimas décadas, a pesar de la implantación de instituciones y leyes de combate al fenómeno; no se vislumbra, por lo menos a medio plazo, posibilidad concreta de rompimiento de ese círculo vicioso; y que, en la escala construida en este artículo, el país permanece en los puestos elevados de la clasificación, configurado como un Estado y sociedad con fuertes trazos extractivitas de carácter perene.

Palabras-clave: corrupción, administración pública - Brasil

\section{The Vicious Circle of Corruption in Brazil: structural boundaries and perspectives of rupture}

The focus of this article lies on identifying and analysing some aspects of the Brazilian Socio-political and economic context in order to understanding corruption, which has been part of this context. Corruption in Brazil has performed a vicious circle in historical terms. Through a qualitative and interpretativist reserch which supported arguments relating theoretical aspects of patrimonialism and rent- seeking added to empirical information of the Brazilian political, social and economic context, this present research has concluded that corruption in Brazil has grown in a rapid way in the last decades, despite the building of institutions and laws to face the phenomenum. Furthermore, it is not possible to find concrete chances of, in a middle term, breaking this vicious circle. The article has provided a scale of corruption and Brazil has occupied high positions in this ranking designing a State and Society with strong traces of extractivism of perenial character.

Keywords: corruption, public administration - Brazil 


\section{Introdução}

Pode-se afirmar que o fenômeno da corrupção, que não figurava como tão relevante pela maioria dos estudiosos da realidade social, econômica e política brasileira, adquiriu, nos últimos anos ou décadas, maior centralidade, ao que tudo indica, pelos sucessivos escândalos que têm marcado a vida política do país. Embora a maior parte dos estudos, senão a totalidade, sobre a realidade brasileira mencione o tema da corrupção, nota-se que poucos têm sido os trabalhos que buscaram fazer uma investigação das suas razões mais estruturais. Esses estudos, em geral, até apresentam e constatam a existência de corrupção, mas sem preocupação em qualificá-la.

Observa-se ainda que a investigação sobre esse tema no Brasil pode ser caracterizada em dois grandes blocos. Em um deles, de senso comum, advoga-se que corrupção sempre existiu no Brasil. Martins (2008, p. 65) se debruça sobre essa situação pontuando que são "recorrentes as manifestações de descontentamento diante dos casos de corrupção", coisa que o brasileiro trata com ironia, deboche ou piadas. "Essa perpetuação da corrupção política produz uma falsa ideia de que ela não tem solução, de que sempre haverá corrupção, de que todos os políticos são corruptos, de que o Brasil não tem jeito!" (MARTINS, 2008, p. 65). O autor enxerga um sentimento da existência de uma corrupção estrutural ao "nos considerarmos os campeões mundiais em corrupção", posição certamente exagerada, embora ponderando que "não fomos nós que a inventamos" (MARTINS, 2008, p. 25). No outro bloco, pensa-se que, ainda que a corrupção possa ser um traço forte da formação política e social do Brasil, ela teria ingressado em outro patamar nas últimas décadas, também havendo dificuldade em precisar quando se entra e que patamar seria esse. A corrupção, assim, seria vista em sua primeira longa fase como pontual, ocasional ou de pequena monta. Já nessas últimas décadas teria assumido um caráter sistêmico; tal como ocorre em uma metástase, quando as células cancerosas se desprendem dos tumores originais se espalhando pelo corpo, a corrupção proliferou no tecido social brasileiro.

No que tange às perspectivas teóricas de enquadramento da corrupção, duas vertentes são claramente identificadas nos estudos que buscam explicar a ocorrência desse fenômeno no Brasil: uma centrada nas teorias da modernização, mais especificamente no conceito de patrimonialismo e seus desdobramentos; a outra está assentada na visão do rent-seeking, localizada na teoria na nova economia institucional (OliveIRA JR.; LUSTOSA DA COSTA; MENDES, 2016).

Neste artigo, o que se busca é lançar mais luz sobre esse debate, procurando avançar o conhecimento que se tem sobre o tema - corrupção no Brasil -, pois é 
sabido ser fundamental conhecer o fenômeno para que se possa agir sobre ele. Para tanto, a investigação foi norteada pela seguinte questão: que aspectos do contexto socioeconômico e político do Brasil redemocratizado reforçam ou possibilitam o rompimento do círculo vicioso da corrupção que o envolve?

A pesquisa desenvolvida teve caráter qualitativo-interpretativista. Essa escolha não foi aleatória, pois decorre da compreensão dos pesquisadores sobre o alcance dessa metodologia, que, como ficará evidenciado no decorrer da apresentação do trabalho, possibilitou um plano de sustentação argumentativo que relaciona aspectos teóricos do patrimonialismo e do rent seeking com informações empíricas do contexto histórico e sociopolítico-econômico do Brasil. Tais informações foram obtidas de autores que, na visão dos pesquisadores, são seminais na literatura especializada. Admite-se também que a corrupção é um fenômeno social, que tem sofrido transmutações apreciáveis ao longo dos últimos anos no Brasil, não obstante esse país ter transitado do regime ditatorial para o democrático.

\section{Bases para o entendimento da corrupção no Brasil}

De início vale registrar que o tema da corrupção só mais recentemente despertou a atenção dos acadêmicos no Brasil. Uma prova inconteste dessa afirmação pode ser encontrada no ranking de citações da Revista de Administração Pública (RAP) que existe desde 1967. Entre os 200 artigos mais citados, levantamento que abrange todos os artigos publicados desde o seu início, apenas um tem no título a palavra corrupção. De autoria de Zani A. Brei (1996), o artigo que se situa entre os 100 primeiros mais citados, é sugestivamente intitulado Corrupção: dificuldades para definição e para um consenso. Por certo, muitos artigos tratam do tema ao falarem de administração pública, reforma do Estado, accountability, mas apenas este com destaque para o termo. Ainda vale mencionar que o artigo se baseia em um referencial teórico com ênfase nos Estados Unidos, não havendo uma linha sequer dedicada ao Brasil. Presume-se que a dificuldade estampada no título do artigo se fazia mais presente no caso do Brasil. Por outro lado, o artigo data de 1996, quando, como veremos adiante, já se tinha elaborações sobre o tema no Brasil.

O ponto de partida deste artigo assume que importa direcionar este estudo para o entendimento do processo histórico brasileiro. De imediato, José Murilo de Carvalho pode dar uma ajuda substancial nessa questão de entender o que é corrupção ou o que não é, bem como quando que ela efetivamente se impregna na vida política brasileira. O autor registra que se fala em corrupção no Brasil há décadas ou até um século, pois "a corrupção foi um tema dos republicanos ao final do Império, repetiu-se em 1930, em 1945, em 1964" (CARVALHO, 2008, p. 69). E qualifica que muitos que a denunciavam viraram em momentos seguintes 
denunciados. Pode-se dizer que a corrupção era quase um mantra para destronar os ocupantes do poder ou derrubar um regime. Ele percebe que a questão ganhou importância a partir de 1989, certamente por conta da nova Constituição, quando "começamos a nos perguntar sobre a natureza, causas e consequências" da corrupção (CARVALHo, 2008, p.70).

Carvalho (2008) leciona sobre o que é corrupção em sistemas políticos diferenciados. Na concepção da república antiga, "uma república seria corrupta se não atendesse ao interesse coletivo" (CARVALho, 2008, p.70). Na concepção moderna, baseada nos EUA, uma república seria corrupta se não atendesse os interesses individuais. Tomando esse foco sistêmico, a república brasileira seria corrupta "desde o início" (CARVAlHo, 2008, p. 71), pois não atendia nem o interesse individual nem coletivo, seria até duplamente corrupta, poder-se-ia adicionar.

Com a redemocratização de 1945 e a relevância assumida pelo udenismo, o foco da corrupção está no comportamento individual, de modo que "corruptas eram as pessoas, eram os políticos getulistas" (CARVALHo, 2008, p.71). O golpe de 64 foi justificado contra os "subversivos e corruptos". Collor, por sua vez, direcionou sua espada contra os "marajás". O autor defende que não existe apenas a concepção moralista, a corrupção do indivíduo, mas também a corrupção política e sistêmica, isto é, a corrupção está embebida no sistema político, no seu funcionamento, na sua lógica, na sua liturgia.

\section{A reflexão recente sobre a corrupção no Brasil}

Retornando à questão das explicações da negligência do tema da corrupção enquanto objeto de análise, observa-se que essa ausência não é tão intensa na produção acadêmica mais recente. Pode-se destacar uma produção que se desenvolve nos anos 1980/90 e outra que começa já nos anos 2000 e se aprofundaria com os governos do PT e, mais ainda, com as manifestações de junho/2013 e os escândalos que vieram à tona. Vale pontuar que, no primeiro lote de contribuições - a dos anos 1980/90 -, argumenta-se sobre uma corrupção mais genérica, difícil de detectar. Os autores parecem se referir a algo distante, meio intangível e difícil de localizar, parece que falam "em tese". Já no segundo lote, no qual se repetem alguns autores, as afirmações são mais enfáticas e diretas, se referindo a objetos concretos e não mais intangíveis. A análise da corrupção saiu de uma esfera mais abstrata para uma mais concreta.

Antes da apresentação dessa produção, importa salientar alguns comentários preliminares sobre o que havia antes dessas décadas de 1980/90 tomando como marco de partida a formação do Brasil moderno com a Revolução de 30. Em 
um primeiro período, debaixo do manto getuliano, além de a pesquisa social no Brasil ainda ser muito incipiente, o tema da corrupção não chamava atenção enquanto problema de análise, embora já houvesse denúncias e reconhecimento de sua existência.

Em um segundo período, 1945/64, período de elevado crescimento econômico, industrialização e modernização, é que surge a expressão "mar de lama" associado à queda de Vargas e também que se cunha a expressão "rouba, mas faz" cingida apenas ao governador do Estado de São Paulo. Novamente, a pesquisa acadêmica não dá mostras de interesse sobre o tema, certamente entendendo que os problemas mais sérios da Nação eram outros, como o desenvolvimento.

O terceiro período, 1964/85, é marcado pela emergência do Estado burocráticoautoritário, sob a tutela dos militares. A produção acadêmica denunciava o regime dentro da escassa margem existente de liberdade de expressão. Não havia espaço nesse período para a investigação da corrupção, dado que o tema retorno à democracia tinha inegavelmente maior importância, bem como o caráter refratário do regime a qualquer controle social. A título de ilustração, até a inflação, um índice de fácil acompanhamento pela sociedade, era camuflado e escondido. É possível especular que, nesse período, tenha se gestado uma nova fase e estrutura de corrupção, dado o tamanho que o Estado (e estatais principalmente) assumiu.

No quarto período, que se inicia com a Nova República, 1985/94, com o encerramento do Estado de exceção, a corrupção passa a ser mais visível, a vir à tona. O ápice desse período chega com o Governo Collor de Mello, e mais especificamente com o chamado esquema PC, no início dos anos 1990. O "rouba, mas faz" teria sido potencializado, mas na vertente talvez do muito rouba e pouco faz. No entanto, a queda de Collor e algumas punições localizadas não foram suficientes para desbaratar a corrupção. Muito pelo contrário, parece que a corrupção se aperfeiçoou de lá para cá e certamente aumentou de escala, o que indicaria que uma corrupção profissional e de maior escala estaria instalada no país. Essa percepção se fundamenta também em Carvalho (2008), que afirma ser maior o tamanho da corrupção de hoje do que no passado, especialmente por causa do crescimento acelerado da máquina estatal, observado desde 1930, o predomínio do Poder Executivo sobre o Legislativo e a impunidade decorrente da ineficiência tanto dos sistemas policiais como do Judiciário. Esse autor, mesmo admitindo a falta de estudos que comparativamente quantifiquem a corrupção ontem e hoje, pontua que esses são alguns dos fatores que ampliaram as oportunidades para as práticas clientelísticas e patrimonialistas no país. Parece se constituir um todo coeso e dirigido para a corrupção. 
Aqui vale o registro de um ato do Governo Itamar Franco, que sucede a Collor após seu impeachment, digno de nota, pois seria o reconhecimento institucional da existência da corrupção e da necessidade de combatê-la. Trata-se da formação de uma comissão especial de combate à corrupção, cujos trabalhos foram desenvolvidos entre dezembro/1993 e dezembro/1994. Criada por meio do Decreto 1.001, de 06/12/1993, a Comissão Especial de Investigação (CEI) era uma instância civil e não governamental constituída por sete representantes da sociedade civil, presidida pelo Ministro Chefe da Secretaria de Administração Federal da Presidência da República, para investigar a mecânica da corrupção no Executivo federal e apresentar soluções para combatê-la. Sem ônus para o Estado, em dez meses de funcionamento (fevereiro a dezembro de 1994), a CEI reuniu documentos recolhidos em diversos ministérios e autarquias federais, produzindo análises que demonstravam a "extensão e a gravidade da corrupção sistêmica" (CARVALHOSA, 1995, p. 11) do Governo Federal, ao tempo em que efetuava recomendações de ações preventivas e corretivas de atos de corrupção.

Entretanto, a CEI foi extinta no início do Governo Fernando Henrique Cardoso, que por meio do Decreto no 1.376 , de 19 de janeiro de 1995, que determinou que o acervo documental proveniente de diligências e investigações realizadas pela comissão ficasse sob a guarda do Ministério da Justiça e transferiu para a Secretaria Federal de Controle do Ministério da Fazenda a responsabilidade pela execução dos procedimentos sobre diligências e investigações da administração pública federal. Entretanto, o paradeiro da documentação produzida pela CEI é desconhecido, tornou-se "mais um arquivo morto" (SIMON, 2003, p. 32).

Contudo, informações sobre os trabalhos desenvolvidos pela CEI podem ser localizadas no livro O livro negro da corrupção, que, coordenado por um dos integrantes da comissão, foi publicado em 1995 ${ }^{1}$. O livro apresenta detalhes da mecânica dos variados esquemas de corrupção existente nos mais diversos órgãos do Governo Federal, bem como as medidas de correção propostas pela CEI. É com base nessa publicação que se tem notícia de que é da comissão, por exemplo, a proposta da edição de um Código de Ética do Servidor Público e da regulação da atividade de lobbying junto ao Congresso Nacional. Como se pode deduzir, o ineditismo dessa iniciativa do Govero Itamar Franco está em fornecer, em níveis nunca visto na nossa história, a agentes da sociedade civil, poderes de realizar procedimentos investigatórios típicos de órgãos intraestatais, já indicando que os órgãos governamentais não teriam a necessária isenção para se autoinvestigarem.

\footnotetext{
${ }^{1}$ A versão e-book de O livro negro da corrupção está disponível para download no site www.muco.com.br.
} 
O período iniciado em 1995, que perdura até os dias de hoje e que pode ser subdivido nos Governos FHC e Lula/Dilma e Temer, de democratização assentada, será tratado mais adiante.

\section{Referencial teórico}

Como dito anteriormente, são identificadas na vertente brasileira duas perspectivas teóricas de enquadramento da corrupção: uma centrada nas teorias da modernização, mais especificamente no conceito de patrimonialismo e seus desdobramentos, e outra assentada na visão do rent-seeking localizada na teoria na nova economia institucional (OLIVEIRA JR.; LUSTOSA DA COSTA; MENDES, 2016).

A utilização do referencial teórico do Patrimonialismo no Brasil ocorre após e a partir da obra clássica Os donos do poder, de Raimundo Faoro, em 1958. É bastante raro encontrar um autor que trafegue por esse referencial nas décadas seguintes até a década de 1990, quando então começa a se tornar referência. Nesse sentido, é oportuno olhar o trabalho de Juarez Brandão Lopes (1976), uma avis rara no uso do patrimonialismo para explicar a realidade brasileira. Convém lembrar que o país vivia no regime de exceção e que vinha de surtos de industrialização dos anos 1930/40/50 em processo de se tornar uma sociedade industrial. À época do escrito do autor, ocorria outro surto de industrialização nos anos 1970, agora sob a égide dos governos militares. O autor em tela reconhece que "o patrimonialismo sobrevive no Brasil, como estrutura, não só nas regiões mais isoladas, como também em pequenas cidades e nas zonas rurais das áreas urbanizadas do país" (BRANDÃo LOPES, 1976, p. 185). Em outras palavras, o autor entende que o patrimonialismo já havia sido vencido nas áreas mais urbanizadas e industrializadas do país. Nessas áreas resistentes, defende o autor, "forças econômicas, sociais e políticas - derivadas do desenvolvimento - estão a mináIo" (BRANDÃo LOPES, 1976, p. 185).

Assim, a aposta do autor, bem como de outros pensadores, é que o desenvolvimento, via industrialização, levaria o país à modernização, à extirpação do patrimonialismo. A aposta era na industrialização, no que ela trazia de novas relações de trabalho, na racionalização do trabalho, da emergência de setores empresariais capitalistas, na burocracia legal-racional e no próprio operariado, todos untados de racionalização. E isto aconteceria, seguindo o raciocínio do autor, mesmo nas áreas mais atrasadas do país, à medida que a industrialização avançasse. Assim, Brandão Lopes não titubeia apostando na "desagregação da sociedade patrimonialista" (BRANDÃo LOPES, 1976, p. 185). 
O que se assistiu historicamente, no entanto, não justifica tamanho otimismo. Mesmo a industrialização tendo avançado, ainda que de maneira errática, e se espalhado por várias regiões do país, tudo isso não foi capaz de erradicar o patrimonialismo.

Bresser Pereira (1995) é um dos que, já nos anos 1990, ao propor a Reforma do Aparelho do Estado, entende que o patrimonialismo está vencido, sendo necessário implantar uma visão mais gerencial para superar os problemas da burocracia weberiana. Pinho (1998), poucos anos depois, se contrapõe a essa visão apontando a resiliência do patrimonialismo. Mas o que vale sublinhar aqui é uma visão de aposta na modernização a partir da economia (industrialização). O que defendemos aqui é que as estruturas políticas do Brasil são demasiado conservadoras para sucumbir a um processo e à lógica da industrialização. Parece possível detectar um amálgama entre forças modernizantes na esfera econômica e forças conservadoras na esfera política, com as primeiras se amoldando às segundas. A política, conservadora, resiste estoicamente à economia modernizante.

Baseado em Pinho e Sacramento (2009), Oliveira Jr, Lustosa da Costa e Mendes (2016) localizam as bases teóricas para a construção do segundo caminho teórico em Klitgaard (1994), Rose-Ackerman (1978 e 2010) e Gonçalves da Silva (2001). Oliveira Jr et al. ensinam que as teorias baseadas na primeira corrente - a do patrimonialismo - tiveram sua vigência até os anos 1990, mas que dessa data em diante as teorias do rent-seeking tornaram-se hegemônicas, principalmente a partir da Nova Economia Institucional e do "neoinstitucionalismo econômico" introduzidas no bojo das reformas do Estado presentes no Brasil exatamente na década de 1990, nos Governos Cardoso. Neste artigo, assume-se que essas abordagens não são mutuamente excludentes. Se o Brasil é um país que não concluiu seu caminho para a modernização e onde o patrimonialismo está longe de ser uma página virada, permanecem presentes esses aspectos decisivos da estrutura política brasileira constituída de um ethos patrimonialista. Assim, mesmo que tenha ocorrido uma reforma do Estado, diga-se, do aparelho do Estado, do Executivo, esta não foi suficiente para abalar suas fundações e colunas patrimonialistas (PINHO, 2016).

As duas correntes teóricas trazidas pelos autores sofrem críticas, o que mostra sua insuficiência em lidar e explicar o fenômeno. Assim, para Avritzer e Filgueiras (2011), a recorrência ao patrimonialismo estreitaria o entendimento do fenômeno ao se assentar em uma perspectiva moralista, gerando um "engessamento crítico das instituições políticas" (Avritzer; Filgueiras, 2011, p. 8). O fundamento moralista se assenta na percepção da corrupção como inerente ao caráter do brasileiro, pontuam os autores. Tal crítica, entretanto, tem seus limites. Por um 
lado, é um aspecto bem intangível, de difícil medição. Por outro lado, é conveniente marcar que o patrimonialismo se dá fundamentalmente na arena do setor público, do Estado (Executivo, Legislativo e Judiciário) e não exatamente na esfera privada, ainda que exista nesta. Mas as decisões fundamentais são tomadas na esfera estatal. Essa visão favorece uma posição de acesso rápido e facilitado da sociedade civil às estruturas de Estado. Assim, se o brasileiro é corrupto, venal, isso se transfere para o Estado. Ora, é abissal, no caso brasileiro, a distância entre Estado e suas estruturas e o cidadão, ainda mais o cidadão comum.

Além disso, não se tem visto nenhum engessamento ou paralisia institucional, muito pelo contrário, têm sido criadas instituições, no âmbito do Estado, de combate à corrupção, mas os avanços não têm reverberado na contenção da corrupção ou na condenação, na escala necessária, dos envolvidos (PINHO; SACRAMENTO, 2009).

Filgueiras (2008, p. 359) tece críticas à visão mais econômica da corrupção pontuando que "a concepção econômica da política democrática cria uma miopia teórica a respeito da corrupção", observando que "a linguagem da economia colonizou o discurso político" reduzindo a política a uma "competição e cooperação de atores racionalmente orientados pelos fins".

Cumpre destacar que, em sistemas patrimonialistas ou neopatrimonialistas, as ações dos agentes se desenvolvem em uma matriz permeada pela confusão entre o público e o privado, assentada em uma sociedade civil frágil que, se sabe, não alcança o que está sendo perpetrado. Assim, os atores se movem com muito maior desenvoltura e facilidade em busca da espoliação do Estado, da coisa pública. $\mathrm{O}$ patrimonialismo no Brasil tem mostrado não só uma grande resiliência (PINHO, 1998) como uma capacidade de se reinventar, longe de ser um resíduo ou um apêndice, uma página virada na nossa construção social e política.

Pensando ainda em termos macro teóricos, pode-se inserir uma outra perspectiva para a análise da corrupção, de lavra mais recente, na qual se pressupõe a existência de uma moldura mais ampla, onde a corrupção se encaixa. Acemoglu e Robinson (2012) fizeram um alentado estudo tomando uma perspectiva de longo prazo, de décadas e séculos, para entender o fracasso e sucesso de impérios ou nações. Os autores pouco se debruçam sobre o Brasil, mas as categorias teóricas que eles criam são úteis para olhar a trajetória da sociedade brasileira e onde se insere a corrupção.

Antes de mais nada, os autores dão centralidade às instituições políticas sendo que estas "é que ditam que instituições econômicas o país terá" (ACEMOGLU; RoBINSON, 2012, p. 33); é a esfera política que determina o que elas são e serão. E de uma maneira geral, "as regras que acabam regendo cada sociedade são 
definidas pela política" (ACEMOgLU; RoBinson, 2012, p. 33). Isto posto, os autores trabalham com os conceitos de instituições inclusivas e extrativistas. Nas inclusivas ocorrem oportunidades de participar do jogo econômico, existe maior liberdade de atuação econômica, bem como existe um sistema jurídico imparcial. As instituições econômicas extrativistas se definem em oposição às inclusivas, tendo como "finalidade a extração da renda e da riqueza de um segmento da sociedade para benefício de outro" (ACEMOGLU; ROBINSON, 2012, p. 60).

"As instituições econômicas inclusivas preparam o terreno também para dois outros motores da prosperidade: tecnologia e educação" (ACEMOGLU; RoBInSON, 2012, p. 61), preocupações não encontráveis naquelas de corte extrativista. Os autores também mostram que arranjos extrativistas podem gerar renda e riqueza, alcançadas através de instrumentos de força, mas estas ficam concentradas e o arranjo não consegue sobreviver por um longo período (ACEMOGLU; ROBINSON, 2012, p. 62). Observa-se, como já ficou claro antes, a existência de uma "forte sinergia entre as instituições econômicas e políticas" (ACEMOGLU; ROBINSON, 2012, p. 63). O poder é concentrado, nas instituições políticas extrativistas, "nas mãos de uma pequena elite e essas impõem poucas restrições ao exercício do poder" (ACEMOGLU; RoBinson, 2012, p. 63). Em consequência, as elites estruturam as instituições econômicas de modo "a extorquir recursos do restante da sociedade" (ACEMoglu; Robinson, 2012, p. 63).

Os autores explicitam em sua tese que "o crescimento econômico e a prosperidade estão associados a instituições políticas e econômicas inclusivas, ao passo que as instituições extrativistas tendem a acarretar estagnação e pobreza" (ACEMOGLU; RoBINSON, 2012, p. 71). Mas os autores também fazem a ressalva de que isso não significa que "as instituições extrativistas sejam incapazes de fomentar crescimento nem que todas as instituições extrativistas sejam idênticas" (ACEMOGLU; RoBInSON, 2012, p. 72). Isso pode ser entendido nos seguintes termos: tudo vai depender do quanto tem a ser extraído e da velocidade de extração, bem como de quanto tempo duram as reservas a sofrerem a extração.

Os detentores do poder em sociedades extrativistas são avessos ao progresso econômico, pois este pode representar uma ameaça aos seus intentos, sendo que "seus interesses são extorquir renda e sustentar seu poder" (ACEMOGLU; RoBINSON, 2012, p. 71). Existe a possibilidade ainda de lutas intra elites. "Para cada elite a se beneficiar do extrativismo, há uma não elite que adoraria substituí-la. Às vezes, as disputas internas levam tão somente à substituição de uma elite por outra" (ACEMoglu; Robinson, 2012, p. 112). 
Um ponto recorrente de instituições extrativistas é a centralização política. Assim, a elite que controla o Estado é capaz de produzir incentivos para a geração de riqueza, "estimulando por sua vez outros a investir de modo a possibilitar que o Estado extraia recursos destes e até simule alguns dos processos que normalmente seriam desencadeados por mercados e instituições econômicas inclusivas" (ACEMOgLU; Robinson, 2012, p. 117).

Ao se fazer um cotejo dessa situação com a teoria baseada no rent-seeking, resta a impressão que esta é bastante leve baseada em um padrão civilizatório muito mais alto do que aquele das sociedades extrativistas. Nestas, o jogo mostrase muito mais aberto e pesado em termos de voracidade, enquanto as sociedades baseadas no rent-seeking estão inseridas em um contexto democrático. A palavra extorquir parece ser a chave para diferenciar sociedades baseadas em um simples rent-seeking e aquelas de perfil extrativista. As sociedades extrativistas dificilmente se assentam em contextos democráticos, o que pode até ocorrer, mas dentro de uma democracia limitada ou uma democracia de fachada. O Brasil parece se inserir, até certo ponto, nesse grupo; a nossa democracia mostra-se limitada e tem sido de difícil compreensão para os analistas. O' Donnell (1991), por exemplo, criou o conceito de democracia delegativa para tentar entender o Brasil e América Latina. Os escândalos registrados no Brasil nas últimas décadas, com ênfase nas três últimas, parecem revelar que o país detém muitos dos componentes de uma sociedade extrativista, ainda que regidos pelos parâmetros de uma sociedade poliárquica. É oportuno registar que parece estarmos frente a um paradoxo, pois, ao se sair do regime ditatorial (1964-1979), seria de se esperar um avanço consistente da democracia, mas este não se concretizou no que tange ao combate efetivo à corrupção, ainda que avanços tenham ocorrido, como será exposto adiante. Nesse contexto, para que se possa lançar luz para a magnitude do fenômeno no Brasil, pode ser útil construir uma escala de corrupção descrevendo estágios e os stakeholders, atores fundamentais, envolvidos. Cumpre destacar que, para a construção dessa escala, não foram levados em consideração quaisquer dados quantitativos, o que pode desde já ser apontado como uma das suas limitações, muito embora essa ausência de informações quantitativas se coadune com a opção da abordagem do estudo que foi realizada: 
Quadro 1 - Estágios de corrupção e envolvimento dos atores relevantes

\begin{tabular}{|l|l|}
\hline $\begin{array}{l}\text { Estágios da } \\
\text { corrupção }\end{array}$ & Atores relevantes envolvidos com corrupção \\
\hline Máximo & $\begin{array}{l}\text { Elites políticas (do Executivo e do Legislativo), elites econômicas, } \\
\text { alta burocracia do Estado, militares e Judiciário }\end{array}$ \\
\hline Médio superior & Todos acima, exceto Militares \\
\hline Médio & Todos acima, exceto Militares e Judiciário \\
\hline Médio inferior & $\begin{array}{l}\text { Segmentos das elites políticas, segmento das elites econômicas e } \\
\text { segmentos da burocracia }\end{array}$ \\
\hline Baixo & Segmentos residuais das elites políticas, econômicas, burocracia \\
\hline
\end{tabular}

Fonte: elaboração própria a partir de Acemoglu e Robinson (2012).

Antes de fazer a diferenciação qualitativa e quantitativa (escala) entre esses estágios, cabe dizer que a corrupção não é um fenômeno normalmente visto a olho nu. Por ser uma transgressão da lei, é sempre escondida, normalmente insidiosamente escondida. Assim, apenas em casos de riqueza completamente incompatível com os ganhos declarados dos agentes, incomensuravelmente superior, pode ser percebida, mas isso também não garante que será pega e punida. Mas, normalmente, o corrupto é um ser mais discreto, até low profile, não exibe sua riqueza, exceto casos patológicos de exibicionismo, presentes cada vez com mais intensidade na sociedade contemporânea das redes sociais.

Estágio máximo: nesse caso, todos os atores relevantes estão envolvidos, ainda que possam existir setores que não façam parte, mas sem força para enfrentar e combater o status quo. Esse é um caso limite, que só pode ocorrer em nações em que a democracia e suas instituições não conseguem ditar as regras de convivência e comportamento. Ocorre mais em nações em que predomina a dominação tradicional no sentido weberiano, ou que se constituíram em Estados falidos. Assim, ainda que no caso do Brasil a corrupção tenha assumido volumes retumbantes, não se alcança esse estágio.

Nesse estágio, podem ocorrer conflitos antropofágicos entre as elites, principalmente se oportunidades extrativistas escasseiam e/ou o potencial de exploração da corrupção se esgotou, não havendo mais de onde tirar o resultado até então auferido. Nesse caso, é de se esperar que setores que combatem a corrupção sejam ostracizados, afastados e, no limite, eliminados. Esse seria o estágio mais sistêmico de extrativismo, todas as forças sociais relevantes se beneficiam dos butins e tudo parece normal. 
Estágio médio superior: nesse caso, os militares estão fora, o que não quer dizer que segmentos ou membros da corporação não participem, marginalmente, ou acobertem esquemas fraudulentos ou ainda façam vistas grossas. Da mesma maneira que no caso anterior, pode ser que nem todos os segmentos desses stakeholders participem, mas são majoritários. Sem os militares, o Judiciário se torna um componente fundamental para a viabilização dos esquemas extrativistas, acobertando ou fazendo vistas grossas para os fatos ou ainda se mancomunando com os condutores de esquemas fraudulentos. Mesmo com a participação do Judiciário, isso não quer dizer que seja sistêmica, mas membros desse Poder que se oponham aos esquemas implantados terão muita dificuldade em reverter o quadro existente, com esforços embalde para combater a corrupção.

Estágio médio: duas instituições-chave, militares e Judiciário, estão fora desse estágio (ainda que membros destas possam participar, mas sem um envolvimento orgânico e sistematizado das instituições, mas de forma pontual). Porém, isso não quer dizer que já não haja mais condições de ocorrência de corrupção de monta apreciável. A convergência de interesses entre as elites políticas, econômicas e burocráticas ainda dispõe de muito poder para realizar os esquemas extrativistas. A forma de combatê-los passa fundamentalmente pelo papel desempenhado pelo Judiciário. Se este tiver independência e espírito investigativo, poderá tentar bloquear as ações extrativistas, mas também podem ser dados alguns benefícios, dentro da lei, para o Judiciário, que esmaeçam o espírito de combate à corrupção. Ou, então, alguns membros do Judiciário se comportam de forma a acobertar os atos extrativistas ainda que possam ter a reprovação de seus pares. Um expediente comum para operacionalizar esse papel do Judiciário é fazer uso das regras existentes, tais como pedir vistas a um processo e "engavetar" o processo de modo a prescrever o crime ou, então, procrastinar a decisão na expectativa de que a sociedade esqueça o ocorrido, ou seja, tudo dentro do que a lei permite. Nessa situação, impera a dubiedade, usa-se o jargão de que as instituições estão funcionando, e a atuação do Judiciário nos esquemas corruptivos se dá no modo bem sutil, não ostensivo.

Estágio médio inferior: nesse estágio, não ocorre uma participação disseminada desses stakeholders, mas alguns segmentos destes, principalmente das elites políticas, econômicas e burocráticas. Esse é um estágio em que a corrupção é pontual, ocasional, ou seja, não frequente, o que a torna de mais difícil percepção. Como ocorre em pequena monta, o Judiciário não é requisitado para cumprir suas funções no tocante ao objeto. Cabe observar que é de se esperar que a corrupção, fora casos mais extremos em que seria constitutiva da nação, comece exatamente nos estágios mais baixos e vá ganhando corpo em direção a estágios mais robustecidos. 
Estágio baixo: nesse caso, ocorre a participação de segmentos residuais das elites políticas, econômicas e burocracia. A corrupção é ocasional, excepcional, longe de articular interesses orgânicos desses stakeholders, envolve apenas segmentos que se beneficiam de oportunidades e de conhecimento do funcionamento da máquina do Estado. Este parece ser o estágio mais adequado a práticas de rent seeking, o que não quer dizer que mobilize apenas baixos montantes. Em geral, as instituições funcionam adequadamente, existe um consenso na sociedade de que a corrupção é condenável e pretensos agentes contraventores não se arriscam, pois as penas são elevadas, bem como a execração pública. Isso não quer dizer que os montantes envolvidos sejam desprezíveis. Em geral, sim, mas podem ocorrer também contravenções de peso. Esse estágio pode estar presente mesmo em sociedades mais avançadas e de democracia consolidada.

Frente a essa exposição, acredita-se que o Brasil esteja situado entre o estágio médio e o estágio médio superior, ficando difícil exarar uma posição mais assertiva principalmente porque as instituições funcionam, existe muita dissimulação e acobertamento entre os agentes interessantes, ficando difícil desvelar o fenômeno em sua extensão e intensidade. Um diagnóstico mais seguro só poderá advir com o prosseguimento de investigações que não poupem nenhum agente contraventor e que atribuam penas de peso aos envolvidos. O Brasil parece pertencer a uma situação mais ecumênica, em que segmentos dos militares/polícia e do Judiciário também fazem parte do banquete da corrupção, mas não enquanto instituições, além de segmentos da classe política, das burocracias e do empresariado, agora já de forma mais intensa e extensa.

Como se pode notar, a escala de estágios de corrupção acima é mais detalhada que a apresentada por Elliott (2002), que trabalha com duas categorias - pequena e grande - vez que especifica como corrupção pequena aquela que é praticada quando agentes privados interagem com funcionários públicos não elegíveis, portanto burocratas, geralmente ocupantes de escalões administrativos inferiores; e como corrupção grande, a que se processa quando agentes privados interagem com funcionários elegíveis e ocupantes dos altos escalões do governo (ELLIOTT, 2002, p. 260)

\section{A produção acadêmica brasileira sobre corrupção}

Esta seção não tem obviamente a pretensão de fazer um levantamento exaustivo da questão da corrupção na academia brasileira, pois se restringe a alguns autores que, na visão deste artigo, mais recorrentemente têm trabalhado o tema. Guillermo O'Donnell, embora argentino, merece aqui ser destacado, porque analisa com robustez a situação brasileira e tem uma produção fincada em elementos 
estruturais da formação social desse país. O autor afirma que uma democracia não institucionalizada se caracteriza pela "fraqueza e baixa densidade de suas instituições", de modo que "outras instituições, não formalizadas, mas fortemente atuantes - especialmente o clientelismo, o patrimonialismo e, certamente, a corrupção -, tomam o lugar daquelas [...]" (O’DonNELL, 1991, p. 30). Nessa situação, a corrupção adquire o status de uma instituição não formalizada e fortemente atuante. Em momento seguinte, O’Donnell (1993) volta-se para a situação em que a efetividade da lei ocorre de forma irregular sobre o território, assim como as relações funcionais em que o Estado é suposto regular. Nessas situações, "estados inefetivos coexistem com esferas de poder autônomas, também baseadas territorialmente" (O’DONNELL, 1993, p.129). Nos estados e nas localidades periféricas ao centro nacional, surgem ou se reforçam "sistemas de poder local que tendem a atingir extremos de domínio violento e personalista - patrimonial, até mesmo sultanístico -, abertos a toda sorte de práticas violentas e arbitrárias" (O'DoNNELL, 1993, p. 129). Ao analisar o grau de presença do Estado, percebe-se um nível muito baixo ou nulo no país em geral, mas mais pronunciado em "partes do Nordeste e toda a Amazônia", exemplos da "evaporação da dimensão pública do estado" configurando "circuitos de poder perversamente privatizados", frequentemente "sultanísticos" (O’DONNELL, 1993, p. 130).

Essas regiões funcionam de acordo com um conjunto de regras não escritas, em que, com burocracias estatais, algumas grandes e complexas, "extremamente politizadas e mal pagas, o próprio significado do termo 'corrupção' se torna vago" (O'DonNELL, 1993, p. 131). Passado um quarto de século, podemos observar como a corrupção era atribuída às regiões mais tradicionais do país. O caso presente do Rio de Janeiro mostra que ou a visão estava equivocada ou este não é único, revelando que a corrupção no Brasil não é exclusiva dos locais menos desenvolvidos, configurando assim uma situação de estágio máximo de corrupção.

Os legisladores das áreas tingidas pela corrupção têm um interesse em "sustentar o sistema de dominação privatizado que os elegeu e canalizar para esse sistema tantos recursos estatais quanto possível", o que depende da "troca de 'favores' com o Executivo e diversas burocracias estatais", e, frente a Executivos "enfraquecidos", acaba ocorrendo uma invasão do topo burocrático do Estado por interesses da corrupção (O'DONNELL, 1993, p. 131). Observa-se aqui um círculo vicioso, em que legisladores e executivos, que posteriormente indicam a parte mais estratégica da burocracia e também do Judiciário, Tribunal de Contas e sistemas de controle em geral, são eleitos em um ambiente de corrupção e não têm qualquer interesse em combatê-lo. Disso resultam dificuldades para a institucionalização plena da democracia, pois esses políticos juntam forças para 
"evitar o surgimento de instituições representativas sólidas" (O'DONNELL, 1993, p. 131). Pior que isso, criam-se condições para a introjeção do autoritarismo, e, assim, nos países fortemente caracterizados pela presença da corrupção, as democracias se baseiam em um Estado esquizofrênico, misturando "importantes características democráticas e autoritárias" (O'DONNELL, 1993, p. 133). O quadro aqui traçado converge com a categorização feita de Estados extrativistas em escala elevada. A percepção da corrupção se torna difícil nessa situação, pois as instituições democráticas estão presentes, o jogo das eleições é realizado, parece tudo estar ocorrendo na normalidade democrática, mas o sistema está carcomido por dentro e só esporadicamente se tem conhecimento público de elementos podres que vazam.

O'Donnell (1993) ainda recolhe elementos estruturais de nossa sociedade que configuram a criação, manutenção e alargamento de propensões corruptivas, com destaque para a degradação do serviço público, onde se forma "um solo perfeito para um enorme crescimento da corrupção" (O’DONNELL, 1993, p. 136), pois "em muitas repartições pouca coisa funciona sem suborno, que é leve para os ricos, mas taxa pesadamente os pobres" (O'DoNNELL, 1993, p. 136). Essa situação pode ser caracterizada como corrupção miúda, mas também é observado que "nos níveis mais altos da burocracia, e mesmo nos médios, a corrupção envolve enormes somas de dinheiro" (O'DONNELL, 1993, p. 136), o que pode se aproximar da situação vivenciada nestas últimas décadas.

Se a corrupção se acentua com as crises, poder-se-ia generalizar também para a crise de 2015. Nesses períodos de crise, as condições da sociedade extrativista se pronunciam mais. Colocando o período sob escrutínio, O’Donnell identifica uma "dessolidarização generalizada", em que alguns agentes atuam com um horizonte de "curtíssimo prazo" e colhem "grandes lucros", sendo uma das estratégias mais importantes "a pilhagem da máquina do estado" facilitada pelo "livre e rápido acesso aos órgãos do estado que podem liberar os recursos esperados" (O’DONNELL, 1993, p. 138). Essa estratégia parece ocorrer também em situações extra crises, dado que o paradigma da corrupção está instalado. "Privilégios e favores de todos os tipos são conseguidos pela coalizão de dimensões mínimas que é capaz de obter as decisões apropriadas de um determinado órgão público" (O’DonNELL, 1993, p. 138), pois os capitalistas na América Latina têm "uma longa experiência de viver da generosidade do estado e da colonização de suas agências. Não precisam encontrar muitos parceiros novos nas burocracias públicas, ou inventar novas maneiras de se envolverem com eles em múltiplas formas de corrupção mútua" (O’DONNELL, 1993, p. 139). 
Em outro momento, O’Donnell (1996) considera que os países da América Latina, no processo de redemocratização, ainda não conseguiram constituir poliarquias plenamente institucionalizadas, mantendo traços de sociedades tradicionais baseadas no particularismo ou clientelismo, compreendendo, entre outros, "a patronagem, o nepotismo, os favores e jeitinhos, até as ações que, sob as normas formais do complexo institucional da poliarquia, seriam consideradas corruptas" (O'DoNNELL, 1996, p. 19). O particularismo associado a um governo delegativo e neopatrimonialista é antagônico a um dos principais elementos da poliarquia: "a distinção comportamental, legal e normativa entre uma esfera pública e uma esfera privada" (O'DONNELL, 1996, p. 19). Observa-se como o patrimonialismo ainda exala o seu perfume como guia de fazer política e exercer o poder no Brasil.

Ponderando que "o particularismo é um importante componente do regime político dessas poliarquias" (O’DonNELL, 1996, p. 20) e que este possui "raízes históricas profundas" (O’DONNELL, 1996, p. 24), ressalta-se a ausência de prestação de contas (accountability), manifesta nos controles que determinadas agências públicas devam exercer sobre as demais (O’DoNNELL, 1996). Nas concepções delegativas, o Congresso, o Judiciário e agências estatais de controle são vistos pelos governantes como obstáculos ao desenvolvimento das tarefas delegadas ao Executivo pelo eleitorado (O'DoNNELL, 1996). E, assim, o Executivo faz esforços no sentido de enfraquecer e desprestigiar essas instituições (O'DONNELL, 1996). E o particularismo ainda seria mais "desmedido" no Congresso e nos partidos, nos tribunais e nas agências de controle criando "tentações muito fortes para a prática da corrupção" (O’DonNELL, 1996, p. 27). Não resta dúvida que a percepção desse autor já visualiza a corrupção como um fenômeno instalado e entranhado nas estruturas do Estado e na convivência deste com o setor privado.

O’Donnell volta ao tema em 1998, chamando atenção para a falta de accountability em relação "às ações de autoridades, eleitas ou não, havendo uma "séria desconsideração" das exigências de submissão à lei e de conferência de prioridade aos interesses públicos (O’DonNELL, 1998, p. 41). A lógica que impera é de que no exercício do poder prevaleça o interesse do benefício próprio, comportamento que se torna "senso comum", generalizado, não ficando restrito aos ocupantes de cargos públicos, mas extenso a "famílias, membros do partido e de clubes, e/ou sócios nos negócios" (O’DonNELL, 1998, p. 42). Em outras palavras, o patrimonialismo se derrama sobre toda a sociedade, não apenas os ocupantes dos cargos públicos e das posições políticas, mas também sobre aspirantes a estas. O que se pode constatar é que se tem uma aparência de que as instituições estão presentes e funcionam, tudo aparentando normalidade, mas tudo dentro de um contexto de burla por dentro das regras instituídas, o que converge com a imagem de um Estado extrativista. 
Como essas agências de controle não funcionam isoladamente, dependendo das decisões tomadas pelos tribunais, especialmente nas situações que envolvem autoridades de posição elevada, o Executivo delegativo procura eliminar, cooptar ou neutralizar essas agências tentando eliminar ou negar a validade de instituições que possam ser potencialmente controladoras (O'DONNELL, 1998), conformando um círculo vicioso nefasto de corrupção e extrativismo.

Essa interdependência para a aplicação de sanções no Brasil é reconhecida como um desafio para a realização completa da accountability também por outros autores. A esse respeito, Power e Taylor (2011), por exemplo, pontuam que a atuação do Congresso pode se caracterizar tanto como proativa, quando se antecipa a situações que devem ser investigadas, quanto reativa, visto que, na maioria das vezes, esse Poder opera impulsionado pelas denúncias recebidas, especialmente dos meios de comunicação. O próprio Ministério Público, não obstante ser reconhecido como o quarto poder da República devido a sua autonomia e ausência de subordinação hierárquica, depende sobremaneira dos esforços prévios da Polícia Federal, que são empreendidos durante o processo de investigação, seguindo dependente das ações dos Tribunais, desta feita para o julgamento dos processos resultantes de suas investigações.

Acrescente-se ainda que, quando ações são dependentes de prosseguimento e julgamento a partir da Suprema Corte, por razão do "foro por prerrogativa de função", o conhecido foro privilegiado, atribuído a ocupantes de cargos de alta responsabilidade pública (Presidente da República, Vice-Presidente, o ProcuradorGeral da República, Ministros e Membros do Congresso Nacional), a sanção pode demorar décadas para ser aplicada. Logicamente, tais instituições não são autônomas em relação à sociedade, tampouco estão imunes às suas pressões, mas é preciso destacar, ainda seguindo esses autores, que essa ligação tanto pode contribuir para melhorar a sua efetividade, quanto comprometer a sua capacidade de efetivamente perseguir e punir infratores, alimentando e protegendo ações de caráter corruptivo.

Wanderley G. dos Santos (1993, p. 9) é outro autor que contribui nesse período, condenando a visão equivocada de buscar "uma teoria que explique o fenômeno da corrupção entre wasps (anglo-saxões, brancos e protestantes), obviamente distinta daquela que serve para reiterar a suposta tendência de pobres e mestiços à imoralidade pública". É de "suma relevância" considerar que a evolução latinoamericana tem uma "peculiaridade" quando comparada com a maioria das experiências das democracias contemporâneas, qual seja, a incorporação das massas à competição política ocorre antes da estabilidade na institucionalização das regras dessa competição (SANTOS, 1993, p. 29). Essa característica explica 
a "instabilidade recorrente" dos países latino-americanos antes que qualquer "perversidade de caráter" (SANTOS, 1993, p. 29). Outra consideração "crucial", da peculiaridade latino-americana, reside no fato de as respostas ao problema da participação ampliada ocorrerem "em um contexto de baixa institucionalização liberal" (SANTOS, 1993, p. 30).

Isto é, a formação social brasileira se distancia da ordem liberal típica, sendo muito mais movida a partir do Estado, de 1930 para cá, e menos pelos mecanismos tradicionais de mercado e competição, ou seja, o patrimonialismo se renova, se moderniza abarcando a industrialização, debaixo do tacape do Estado. Isso quer dizer que a corrupção não deve ser buscada fundamentalmente na lógica do mercado e das empresas - ou seja, a explicação rent-seeking não encontra ressonância no Brasil como em países de tradição liberal -, mas na lógica do patrimonialismo incrustado no Estado em simbiose com o setor privado.

\section{A produção acadêmica mais recente sobre corrupção}

A partir de agora, o foco do artigo será a produção mais recente, especialmente alguns estudos que se desenvolveram no final do século passado até o presente (2018). O discurso acadêmico que antes era genérico e até vago, embora estruturado, mais recentemente passou a ser mais focado. O interesse maior no estudo da corrupção parece residir na percepção de um ponto de inflexão, de difícil datação, em que o fenômeno da corrupção teria assumido uma nova escala, patamar. Os eventos de junho de 2013 e seus desdobramentos também constituem um referencial para a abordagem do fenômeno.

O Governo Collor, como visto, mostra-se como um ponto de inflexão no tocante à revelação sobre a existência da corrupção no Brasil. Lastreado em um projeto de "absolutização do poder Executivo" (NogueIRA, 1998, p. 132) e exalando um "amadorismo", "pretensão", "arrogância" e "voluntarismo" (NogUEIRA, 1998, p. 132), é retirado do poder através de "um processo de impeachment, inédito na vida republicana, que desbaratou um enorme esquema de corrupção e de manipulação privada da coisa pública" (NogueIRA, 1998, p. 137). Ainda que o montante não tenha sido demonstrado, o adjetivo - enorme - indica uma fase que se anuncia como de montantes elevados. Se, antes, a corrupção estava presente, sendo impossível desconhecê-la, agora a voz torna-se mais clara na denúncia, ingressando em outro patamar qualitativo e quantitativo.

Sorj (2001, p. 13) atribui centralidade ao patrimonialismo, rejeitando uma visão de que este seja um "fenômeno folclórico em um país 'atrasado'" e reconhecendo a existência de um "moderno patrimonialismo brasileiro" que se associa a "extrema 
desigualdade social, a impunidade de suas elites e o abandono dos setores mais pobres da população".

Esse patrimonialismo entra em choque com uma sociedade que se moderniza e "passa a ser percebido como a primeira fonte dos problemas sociais e como uma agressão aos valores da justiça, da igualdade e da convivência democrática" (SORJ, 2001, p. 14), assentado em relações de imbricação entre os interesses dos grupos dominantes e o Estado, a impunidade e o descontrole da máquina governamental. (SORJ, 2001).

José de Souza Martins (2011) traz uma importante contribuição ao estudo da corrupção, situando-a na lógica do sistema político implantado historicamente no Brasil, a ver, "o conceito de corrupção como se difunde na sociedade brasileira hoje [...] atinge todo o sistema clientelista baseado ainda em fortes componentes da dominação patrimonial" (MARTINS, 2011, p. 96). O que nos tange são o clientelismo e o patrimonialismo, que orientam a vida política, econômica e social. "Nesse sentido, quase toda a população, sem disso ter consciência, está de algum modo real ou potencialmente envolvida em corrupção" (MARTINS, 2011, p. 96). Falando do caso Collor, em que o Presidente não foi preso, situação que pode ser estendida para outros casos, não só de presidentes, o autor pontua que "pode ter confirmado na mente popular a ambiguidade do conceito de corrupção e, sobretudo, a ambiguidade da política brasileira" (MARTINS, 2011, p. 96). "Não foi diferente o que aconteceu no caso do mensalão, em 2005/2006" (MARTINS, 2011, p. 97), como não havia sido no episódio dos "anões do orçamento" (1993/94), como ainda no "mensalão" do governo Arruda, no DF em 2010. Essa sucessão de escândalos, que ainda não inclui o "petrolão" e casos arquivados, conduz a uma "certa ansiedade por um Estado moderno" (MARTINS, 2011, p. 97), de base weberiana, capaz de mudar esse quadro de círculo vicioso.

Já focando os anos mais recentes e sob os eflúvios dos eventos de junho/2013, José Murilo de Carvalho (2014, p. 235) coloca o tema nos seguintes termos: “Corrupção não é coisa nova entre nós, sempre existiu de um modo ou de outro. Contra ela se tem reclamado desde que o Brasil é Brasil. É difícil dizer se ela tem aumentado ou diminuído", atestando a dificuldade de análises quantitativas do fenômeno. Se o autor aqui coloca uma dúvida, adiante não titubeia quando afirma que aumentaram "as oportunidades de corrupção ativa e passiva por ter crescido o tamanho do Estado" (CARVALHo, 2014, p. 235), o que já teria ocorrido no período militar, lembrando ainda que parte considerável dos políticos de hoje foi formada naquele período. Por outro lado, o que tem mudado tem sido "a reação pública" (CARVAlHo, 2014, p. 235). Em sua abordagem, o autor elenca todos os avanços feitos no que tange ao aperfeiçoamento dos controles da administração pública e da 
classe política, como a LRF e a Lei da Ficha Limpa, mencionando que o episódio do mensalão foi acompanhado pela opinião pública "com interesse nunca antes visto em nossa história política" (CARVALHO, 2014, p. 236). As condenações realizadas foram "um marco em nossa história jurídica" (CARVALHo, 2014, p. 237). No entanto, há que se registrar que "Ientidão e ineficiência continuam sendo a marca do sistema judiciário" (CARVALHO, 2014, p. 242), o que vem a representar um acobertamento da corrupção. Lembrando que o autor escreve em 2012: "excetuando-se o julgamento do mensalão, a regra ainda é a impunidade dos acusados graças aos infindáveis recursos e apelações processuais" (CARVALHO, 2014, p. 242). Em síntese, apesar dos avanços, as estruturas de corrupção montadas no país há décadas ainda mantêm uma apreciável blindagem, ainda que esta venha se reduzindo, como se expressa no posicionamento de setores do Judiciário.

Considerando artigos que tomam os eventos de junho de 2013 como um ponto de inflexão, Bucci (2016, p. 16) atribui a esses eventos uma das razões da queda da Presidente Dilma, "alavancada pelas denúncias de corrupção, pela decomposição da base do governo no Congresso etc.". Os eventos eclodiram "contra a impunidade da corrupção generalizada", bem como pelas "revelações de malversação do erário em seu governo" (Buccl, 2016, p. 16), entre outros fatores. Vale notar que nesse momento a corrupção já é vista como generalizada e não mais como algo um tanto etéreo ou pontual. Se queremos fazer uma ponte com a visão do rent-seeking, seria um rent-seeking desenfreado. O autor tem uma percepção sistêmica do fenômeno ao apontar que a Presidente não conseguiu perceber a existência de uma "máquina pública encarquilhada e os políticos profissionais especializados em parasitá-la" (Buccl, 2016, p. 17).

O relato de Bucci (2016, p. 17) é típico de situações de Estado extrativista, destacando ainda como marca da Presidente a incapacidade de perceber "a trama de compromissos que a amarrava a um modo arcaico de produção de lucro, com base na promiscuidade entre o público e o privado", expressão certeira de patrimonialismo. Mas não só à Presidente é atribuída a responsabilidade, mas também aos partidos de oposição. "Todos boiaram" (Buccl, 2016, p. 18), o que indica que a corrupção é sistêmica, não sendo monopólio de um único partido ou de poucos e onde se percebia pouco empenho em efetivamente enfrentar o problema.

E, ao se referir à Operação Lava Jato, expõe que a voz das ruas clamando contra a corrupção não foi ouvida "pelos políticos - nem da situação nem da oposição" (BucCl, 2016, p. 141). Se no mensalão - a ação Penal 470 - ocorreu a condenação e prisão de políticos de proa e a estimativa de desvios em torno de 140 milhões de reais em 2005/2006, agora nas investigações da Lava Jato "os números eram de outra escala" (Buccl, 2016, p. 142). Os resultados apurados pela Operação Lava Jato 
mostram que até março deste ano (2018) a operação já registra 183 condenações contra 119 pessoas, em que o valor total do ressarcimento pedido (incluindo multas) já beira quarenta bilhões de reais; os crimes denunciados envolvem o pagamento de propina de mais de seis bilhões; e onze bilhões e meio de reais são alvo de recuperação mediante celebração de acordos de colaboração (MINISTÉRIO PÚBLICO FEDERAL, 2018). Esse fato mostra como a corrupção dá um salto impressionante, e isso em um horizonte de apenas uma década.

Nogueira (2013, p. 20) também dá ênfase aos eventos de 2013, argumentando que estes não se voltaram "contra um governo em particular, mas contra todos governos: contra o sistema político, seus atores, seus procedimentos e sua cultura". As manifestações voltaram-se contra um sistema político que "permite o enriquecimento de certos atores e a disseminação de ilícitos de todo tipo" (NogueIRA, 2013, p. 20) e ocorreram no bojo de uma crise geral. "A corrupção cresceu ininterruptamente. Os partidos políticos seguiram em frente como associações parasitárias, sem vida e sem ideias", configurando-se uma situação de "desperdício e o uso suntuoso de recursos públicos pela elite política e administrativa (Executivo, Legislativo e Judiciário) " (NogUEIRA, 2013, p. 20), o que se tornou uma crise sistêmica, bem próxima do que apontamos como sociedades extrativistas. Essa situação, que conforma uma "perversão sistêmica" (NogUEIRA, 2013, p. 20), torna-se "mais grave" com a chegada do PT ao poder federal, partido que marcou a política brasileira de forma positiva, mas que se afastou de seus ideais iniciais, que "sujou as mãos" (NogUEIRA, 2013, p. 23). Nos governos petistas, não só foram reproduzidas "as bases do clientelismo, do patrimonialismo e da corrupção" como também isso "funcionou como combustível adicional de frustração e indignação" (NogueirA, 2013, p. 23).

Escrevendo sobre corrupção em 2012, Nogueira (2013, p. 205) pontua que "a corrupção é cada vez mais vista", sendo percebida como "um problema de larga escala", o que leva o autor a questionar se a corrupção tem aumentado ou "nossa sensibilidade diante dela que aumentou?" Aumentou mesmo o montante da corrupção, o fenômeno ultrapassou "a dimensão do razoável? " (NoGUEIRA, 2013, p. 205). O uso da expressão "dimensão do razoável" parece significar que a corrupção seria tolerada em níveis mantidos dentro do razoável, mas que estes teriam sido de longe ultrapassados e não mais tolerados. Se existe rent-seeking, seus níveis seriam estratosféricos, mostrando que o referencial de Estados extrativistas associado com patrimonialismo parece dar mais conta de uma explicação do que o rent-seeking.

Nogueira (2013, p. 205) também entende que não existe "monopólio por parte deste ou daquele grupo, partido político ou entidade", estando o fenômeno "disseminado", posição que também se aproxima das sociedades extrativistas. 
De fato, a profusão de escândalos de corrupção que se tem conhecido desde a restauração do desenho democrático, os quais afluem em todos os Poderes do Estado e níveis de governo, evidencia que, no Brasil, a corrupção não se vincula ou subordina a um partido único, mas é multipartidária.

O caminho que a corrupção tomou no país assumiu um caráter sistêmico estando "entranhada, como um componente oculto, não reconhecido, no imaginário e na cultura política da sociedade" (NogUEIRA, 2013, p. 207). Considerando que nenhuma sociedade está imune a este fenômeno, deve-se observar que "a questão é de grau e, evidentemente, de impacto sobre o conjunto da coletividade" (NogUEIRA, 2013 , p. 207). Mesmo com os órgãos de controle que têm sido criados no contexto brasileiro, a corrupção se converteu em problema "absurdamente recorrente" (NogueirA, 2013, p. 212). Sacramento e Pinho (2016, p. 210), ao analisarem a trajetória da answerability, uma das dimensões da accountability, convergiram com esse entendimento, pois concluem que as alterações institucionais formais adotadas no plano federal, entre 1985 e 2014, evidenciaram que "o estabelecimento de novo arcabouço de leis e organismos assentado em uma sociedade de base patrimonialista, gera muita confusão e pouca efetividade, expressando a persistência de traços conservadores nas estruturas institucionais".

Isso quer dizer que, mesmo com a tomada de consciência sobre a questão e ações, instituições e leis criadas, a corrupção não só resiste como mostra permanência e exuberância. Tudo isso parece indicar que estamos naquele estágio em que atores estratégicos estão suficientemente estruturados e protegidos para continuar agindo segundo formas corruptas.

Nogueira (2013) também coloca um ponto defendido neste artigo, qual seja, apesar de todo avanço de mapeamento e enquadramento, "a corrupção brasileira não é tão bem conhecida como se pensa e como deveria ser" (NOGUEIRA, 2013, p. 210). "Protegidos, afilhados e "aspones" pertencem à pré-história da corrupção brasileira" (NOGUEIRA, 2013, p. 211), pois estas seriam práticas "quase ingênuas" frente à complexidade, sistematização e espraiamento que o fenômeno assumiu.

Para finalizar, Martins (2011) é enfático quando afirma: “é impossível entender o Brasil tradicional, o Brasil moderno e já nesta altura o Brasil pós-moderno, sem levar em conta esta tensa combinação de moderno e tradicional que freia o nosso desenvolvimento social e político e que se renova a cada momento" (MARTINS, 2011, p.8). Isto posto, o Brasil se configura como "uma sociedade de história lenta", as mudanças ocorrem muito lentamente, de modo que existe "um Brasil moderno pagando propina para se viabilizar" (MARTINS, 2011, p. 8), e propina aqui pode ser compreendida tanto no sentido literal como metafórico. 


\section{Considerações Finais}

O escopo deste artigo consistiu em identificar e analisar aspectos do contexto socioeconômico e político do Brasil redemocratizado que reforçam ou ameaçam de rompimento o historicamente construído círculo vicioso da corrupção que o envolve. Concluiu-se que a corrupção no Brasil tem avançado aceleradamente nas últimas décadas, apesar da implantação mais recente de instituições e leis de combate ao fenômeno, e que não se vislumbra, pelo menos no médio prazo, possibilidade concreta de rompimento desse círculo vicioso. O que se pôde constatar no percurso desta investigação foi que a prática da corrupção, assim como o patrimonialismo - ainda que não seja possível quantificar objetivamente a corrupção praticada no país, tanto de períodos anteriores como do atual, fato que não deixa de ser uma das limitações tanto dos estudos que serviram de base para a análise, como também ao que se apresenta aqui -, ainda permanece sistêmica, resiliente e de difícil punição, o que seria típico de sociedades extrativistas ou quase-extrativistas e ainda mais de história lenta.

Dentre as razões para diagnóstico tão tenebroso, apresentadas ao longo da exposição, pode-se destacar, ao menos, que: os escândalos que afluem de Norte a Sul do país, envolvendo todos os Poderes, níveis de governo, partidos políticos e agentes políticos e públicos, em conluio com o setor privado, caracterizam a prática da corrupção no Brasil como sistêmica. As instituições econômicas e governamentais, grosso modo, apresentam comportamento que mais se assemelha à forma extrativista e cada vez menos à inclusiva; a multiplicidade desses escândalos, não obstante as muitas alterações institucionais formais que foram adotadas com o fim específico de combater a corrupção, principalmente no plano federal, a caracteriza como resiliente, pois sequer tais alterações foram suficientes para evitar as práticas que se constituíram nos escândalos denominados por mensalão e petrolão; já a interdependência das agências para a aplicação de sanções, bem como as condições estabelecidas para se ter o direito ao "foro por prerrogativa de função", que no Brasil é atribuído a diversos ocupantes de cargos de alta responsabilidade pública, caracterizam-na como de difícil punibilidade.

Assim, conclui-se que a superação da corrupção ou seu rebaixamento para níveis "suportáveis" no Brasil demanda mudanças radicais, as quais não se limitam à estrutura política e social, vez que ações de reparos às fragilidades institucionais existentes, tais como no que tange à aplicação das leis, ao funcionamento dos partidos, transparência etc., somente para citar algumas, também são necessárias. Na escala construída neste artigo, uma das contribuições deste trabalho, o Brasil foi acomodado nos postos elevados da classificação, configurando uma sociedade com fortes traços extrativistas de caráter perene, mas que também se mostra consciente do problema e da necessidade de enfrentá-lo, o que já tem sido feito em parte. 


\section{Referências bibliográficas}

ACEMoglu, Daron; Robinson, James. Por que as nações fracassam. Rio de Janeiro: Elsevier, 2012.

Avritzer, Leonardo; FilgueIRAS, Fernando. Corrupção e controles democráticos no Brasil. Brasília, DF: Cepal; Ipea, 2011.

BRANDÃo LOPES, Juarez R. Desenvolvimento e mudança social. São Paulo: Editora Nacional. Brasília. INL1976

BRASIL. Decreto no 1.001, de 6 de dezembro de 1993. Disponível em: <http://www. planalto.gov.br/ccivil/decreto-lei/del2848.htm.> Acesso em 03 de fevereiro de 2018.

BREI, Zani Andrade. Corrupção: dificuldades para definição e para um consenso. Revista de Administração Pública, Rio de Janeiro, v. 30, n. 1, p. 64 a 77, abr. 1996.

Bresser Pereira, Luiz Carlos. Estado, sociedade civil e legitimidade democrática. Lua Nova [online], n. 36, p. 85-104, 1995.

BucCl, Eugenio. A forma bruta dos protestos. São Paulo: Companhia das Letras, 2016 CARVAlho. José Murilo de. Passado, presente e futuro da corrupção brasileira. In: AVritzer, Leonardo et al. (Orgs.). Corrupção: ensaios e críticas. Belo Horizonte: Editora UFMG, 2008.

Carvalho, José Murilo. Cidadania no Brasil. O longo caminho. Rio de Janeiro: Civilização Brasileira. 2011.

Quem transgride o quê. In: CARDoso, Fernando Henrique; MoreIRA, Marcílio Marques (Coords.). Cultura das transgressões no Brasil: lições da História. São Paulo: Instituto Brasileiro de Ética Concorrencial (ETCO); Instituto Fernando Henrique Cardoso (iFHC), 2008.

CARValhosa, Modesto. Os dez meses de atuação da CEI (fevereiro a dezembro de 1994). In: CARVAlhosa, Modesto. O livro negro da corrupção. Rio de Janeiro: Paz e Terra, 1995.

ELLIOTT, Kimberly Ann. A corrupção como um problema de legislação internacional: recapitulação e recomendações. In: ELLIOTT, Kimberly Ann (org.). A corrupção e a Economia global. Tradução de Marsel Nascimento Gonçalves de Souza. Brasília: Editora UnB, 2002. p. 255-339

FILGUeIRAS, F. Marcos teóricos da corrupção. In: AVRITZER, L. et al. Corrupção: ensaios e crítica. Belo Horizonte: Editora UFMG, 2008.

GONÇALVES DA SILVA, M.F. A economia política da corrupção no Brasil. São Paulo: Editora Senac, 2001.

KLITGAARD, R. A corrupção sob controle. Rio de Janeiro: Jorge Zahar, 1994

Ministério Público Federal (MPF). Resultados da Operação Lava Jato. Disponível em: $\quad$ http://www.mpf.mp.br/para-o-cidadao/caso-lava-jato/atuacao-na-1ainstancia/parana/resultado. Acessado em 20 de março de 2018.

MARTIns, José Antonio. Corrupção. São Paulo: Globo, 2008.

MARTInS, José de Souza. A política no Brasil - lúmpen e místico. São Paulo: Contexto, 2011. 
Nogueira, Marco Aurélio. As ruas e a democracia. Ensaios sobre o Brasil contemporâneo. Brasília. Contraponto. 2013.

As possibilidades da política. São Paulo. Paz e Terra. 1998.

O’DonnelL, Guillermo. Democracia Delegativa? Novos Estudos Cebrap, n 31, 1991.

Sobre o Estado, democratização e alguns problemas conceituais. Novos Estudos Cebrap, São Paulo, n. 36, jul. 1993.

Accountability horizontal e novas poliarquias. Lua Nova, São Paulo, n. 44, p. 27-54, 1998.

OliveIRA JR., Temístocles Murilo; LUSTOSA DA COSTA, Frederico José; MENDES, Arnaldo Paulo. Perspectivas teóricas da corrupção no campo da administração pública brasileira. Características, limites e alternativas. Revista Serviço Público, Brasília, v. 67 (especial), p. 111-138, 2016.

PINHo, José Antonio G. de. Reforma da administração pública no Brasil: a resistência do "bunker" patrimonialista e a reforma que não acontece. Sociedade, Contabilidade e Gestão, UFRJ, v. 11, n. 3, 2016.

- Reforma do aparelho do Estado: limites do gerencialismo frente ao patrimonialismo. Organizações \& Sociedade, v. 5, n. 12, p.59-79, 1998.

Pinho, José Antonio Gomes de; SACRAMEnto, Ana Rita Silva. Accountability: já podemos traduzi-la para o Português? Rev. Adm. Pública, Rio de Janeiro, v. 43, n. 6, p. 1343-1368, Dec. 2009. Disponível em <http://www.scielo.br/scielo.php?script=sci_ arttext\&pid=S0034-76122009000600006\&Ing=en\&nrm=iso>. Acessado em 20 Mar. 2018. http://dx.doi.org/10.1590/S0034-76122009000600006.

POWER, Timothy J; TAYLOR, Matthew M. Accountability Institutions and Political Corruption in Brazil. In POWER, Timothy J; TAYLOR, Matthew M. (Eds) Corruption and Democracy in Brazil: The Struggle for Accountability. University of Notre Dame Press. 2011.

Rose-ACKerman, S. Corruption: a study in Political Economy. Nova lorque: Academic Press, 1978.

The institutional economics of corruption. In: Graaf, G.; Maravic, P.; Wagenaar, P. The good cause: theoretical perspectives on corruption. Barbara Falls, MI, EUA: Barbara Budrich Publishers, 2010. p. 47-63.

Sacramento, Ana Rita Silva; Pinho, José Antonio Gomes de. The process of implementing answerability in contemporary Brazil. Rev. Adm. Pública, Rio de Janeiro, v. 50, n. 2, p. 193-213, abr. 2016. Disponível em <http://www.scielo.br/ scielo.php?script=sci_arttext \&pid=S0034-76122016000200193\&Ing=en\&nrm=i so>. Acessado em 02 Mar. 2018. http://dx.doi.org/10.1590/0034-7612147614.

SAntos, Wanderley G. dos. Razões da desordem. Rio de Janeiro: Editora Rocco, 1993.

Simon, Pedro. O país dos clandestinos. Brasília. Senado Federal. 2003. Disponível em <http://www.senado.gov.br/senadores/Senador/psimon/livros/livro029.pdf>. Acessado em 05 de fevereiro de 2018.

SORJ, Bernardo. A nova sociedade brasileira. Rio de Janeiro: Zahar Editor, 2001. 


\section{José Antonio Gomes de Pinho}

Doutor em Regional Planning pela University of London, Reino Unido. Atualmente é professor titular aposentado da Escola de Administração da Universidade Federal da Bahia (UFBA) e em processo de pós-doutoramento na Fundação Getulio Vargas (FGV). Contato: jagp@ufba.br.

\section{Ana Rita Silva Sacramento}

Doutora em Administração pela Universidade Federal da Bahia (UFBA). Atualmente é Auditora Fiscal aposentada da Secretaria da Fazenda do Estado da Bahia, Vice-diretora e Coordenadora do Curso de Administração da Faculdade Anísio Teixeira de Feira de Santana. Contato: ana.sacramentos@uol.com.br. 